\title{
Mechanism of minimum quantity lubrication in high-speed milling of hardened steel
}

\author{
Y.S. Liao, H.M. Lin* \\ Department of Mechanical Engineering, National Taiwan University, Taipei 106, Taiwan
}

Received 2 November 2006; received in revised form 6 January 2007; accepted 13 January 2007

Available online 6 February 2007

\begin{abstract}
The rapid wear rate of cutting tools due to high cutting temperature is a critical problem to be solved in high-speed machining (HSM) of hardened steels. Near-dry machining such as minimum quantity lubrication (MQL) is regarded as one of the solutions to this difficulty. However, the function of MQL in HSM is still uncertain so far which prevents MQL from widely being utilized in the machining of hardened steels. In this paper, the mechanism of MQL in HSM of hardened steel is investigated more comprehensively. Comparing with dry cutting, the tool performance can be enhanced by MQL under all cutting speeds in this study. It is found that MQL can provide extra oxygen to promote the formation of a protective oxide layer in between the chip-tool interface. This layer is basically quaternary compound oxides of $\mathrm{Fe}, \mathrm{Mn}, \mathrm{Si}$, and $\mathrm{Al}$, and is proved to act as diffusion barriers effectively. Hence, the strength and wear resistance of a cutting tool can be retained which leads to a significant improvement of tool life. It is found that there exists an optimal cutting speed at which a stable protective oxide layer can be formed. When cutting speed is lower than this speed, there is less oxide layer and the improvement of tool life is less apparent. As the cutting speed is far beyond the optimal value, the protective layer is absent and the thermal cracks are apt to occur at the cutting edge due to large fluctuation of temperature. Resultantly, application of MQL is inappropriate in the extreme high-speed cutting condition irrespective of its little increase in tool life. Based on this study, it is concluded that the tool life can be effectively improved by MQL in HSM of NAK80 hardened steels when cutting parameters are chosen properly. (C) 2007 Elsevier Ltd. All rights reserved.
\end{abstract}

Keywords: High-speed machining; Hardened steel; Minimum quantity lubrication; Mechanism; Protective oxide layer

\section{Introduction}

In recent years, high-speed machining (HSM) technology is becoming matured owing to the advance of machine tool and control system. In comparison with the conventional methods, HSM not only exhibits a higher metal removal rate but also results in lower cutting force, better surface finish, no critical heat of the workpiece, etc. HSM has long been applied in die and mold manufacturing. Results show that it is competitive to electrical discharge machining in certain aspects. But the rapid wear rate of the cutting tool due to high cutting temperature generated during the process still remains unsolved.

Generally speaking, the cutting fluid applied in the machining process is considered to act as cooling and

\footnotetext{
${ }^{*}$ Corresponding author. Tel.: +886492563489 ; fax: +886492565674 .

E-mail address: t177@nkc.edu.tw (H.M. Lin).
}

lubricating agent, hence the cutting temperature can be reduced and the tool life and machined surface finish can be improved. However, in the intermittent cutting such as milling operation, especially in high-speed cutting, the large fluctuation of cutting temperature could cause thermal cracks on the cutting edge and subsequently leads to failure of a cutting tool due to edge fracture [1-3]. Besides, there are serious environmental pollution and waste disposal problems when flood coolants are used. In order to alleviate the above-mentioned negative effects, near-dry machining such as minimum quantity lubrication (MQL) has been developed and introduced in last decade.

Several studies on the application of MQL in machining of steels had been conducted [4-14]. It was demonstrated that MQL could be utilized in the drilling and turning processes, whereas its application in milling process, especially in high-speed milling of hardened steel, has rarely been studied. Investigations into the chemical 
adsorption of oxygen on the newly machined surface in a controlled atmospheric chamber were carried out to study the tribological behavior of MQL in turning of steel $[15,16]$. It was suggested that biodegradable synthetic esters exhibited an appreciable ability to form a chemisorbed film compared with vegetable oils, and the adsorption activity of esters can further be increased with abundant supply of oxygen. However, the above-mentioned studies were carried out under low cutting speed (such as $12 \mathrm{~m} / \mathrm{min}$ ) condition. The purpose of this study is to investigate more comprehensively the mechanism of MQL in HSM of hardened steel, so as to bring it to reality.

\section{Experiments}

The experiments were conducted on a vertical high-speed machining center. The work material was NAK 80 mold steel (similar to AISI P21, 41HRc) with the chemical composition of $0.15 \% \mathrm{C}, 0.30 \% \mathrm{Si}, 3.0 \% \mathrm{Ni}, 1.5 \% \mathrm{Mn}$, $0.30 \% \mathrm{Mo}, 1.0 \% \mathrm{Al}$, and $1.0 \% \mathrm{Cu}$, and it was prepared in $100 \times 100 \times 80 \mathrm{~mm}$ block. The Sandvik indexable carbide insert (R390-11T308M-PM 1025) coated with TiAlN and TiN, which could provide higher heat resistance, was mounted on a $16 \mathrm{~mm}$ diameter end-mill with an inclination angle of $8^{\circ}$ and a top rake angle of $20^{\circ}$.

The end-milling tests under dry cutting and MQL conditions were carried out. A less viscous biodegradable synthetic ester, Castrol Carecut ES3 $\left(5\right.$ centistoke at $\left.40^{\circ} \mathrm{C}\right)$, was used for MQL machining. The MQL oil mists were supplied with a Steidle micro lubricating system (Lubrimat L50) in a flow-rate of $10 \mathrm{ml} / \mathrm{h}$ at a pressure of $0.45 \mathrm{MPa}$.

The cutting speed, $V_{\mathrm{c}}$, was set at 300,400 , and $500 \mathrm{~m} / \mathrm{min}$. The feed rate, $f_{z}$, was set at $0.10,0.15$, and $0.20 \mathrm{~mm} /$ tooth. The axial depth of cut, $a_{\mathrm{p}}$, and the radial depth of cut, $a_{\mathrm{r}}$, were 0.3 and $5 \mathrm{~mm}$, respectively. The cutting forces were recorded by a Kistler dynamometer. Tool wear was measured by means of a NIKON-MM40 toolmaker's microscope and was examined by the use of SEM and EDAX (energy dispersive X-ray analysis) on JEOL$6360 \mathrm{LV}$ unit. Tool life in terms of the total length of cut was recorded after a tool life criterion of $0.1 \mathrm{~mm}$ maximum flank wear/groove wear has reached [1,17]. In the paper this is defined as the end of cutting. Workpiece surface roughness, $R_{\mathrm{a}}$, was measured at three points along the cutting direction (i.e. along $100 \mathrm{~mm}$ direction) with a portable Taylor-Hobson surface-detector (Type Surtronic $3+)$.

\section{Results and discussions}

The tool life in dry and MQL machining is given in Fig. 1. It shows that the tool life can be enhanced apparently by MQL as compared to dry cutting at the relatively low speed cutting such as $300 \mathrm{~m} / \mathrm{min}$. While under higher speed cutting condition, the improvement of tool life is less significant. The discussion about how MQL affects the cutting performance, especially tool life, is given below. a

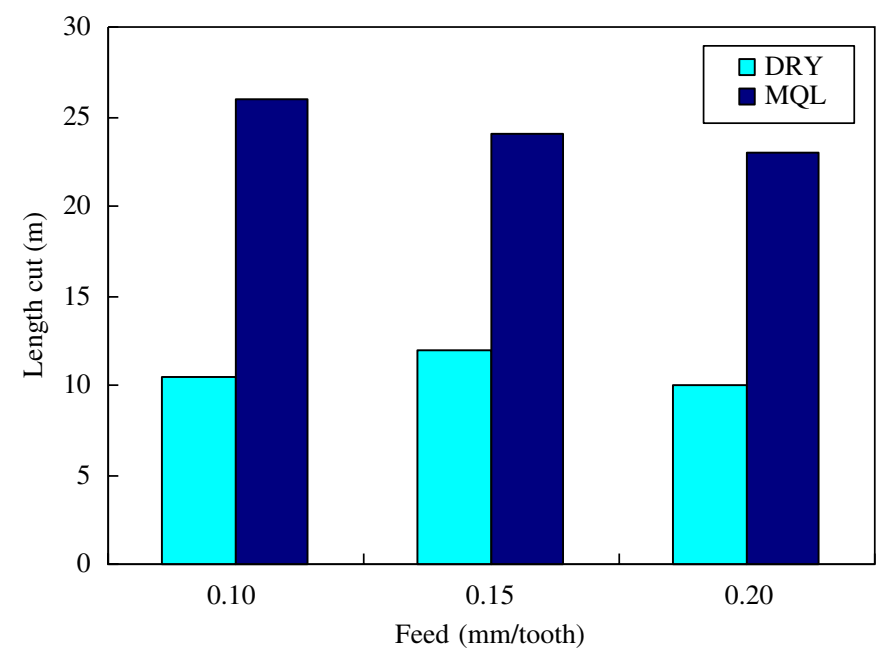

b

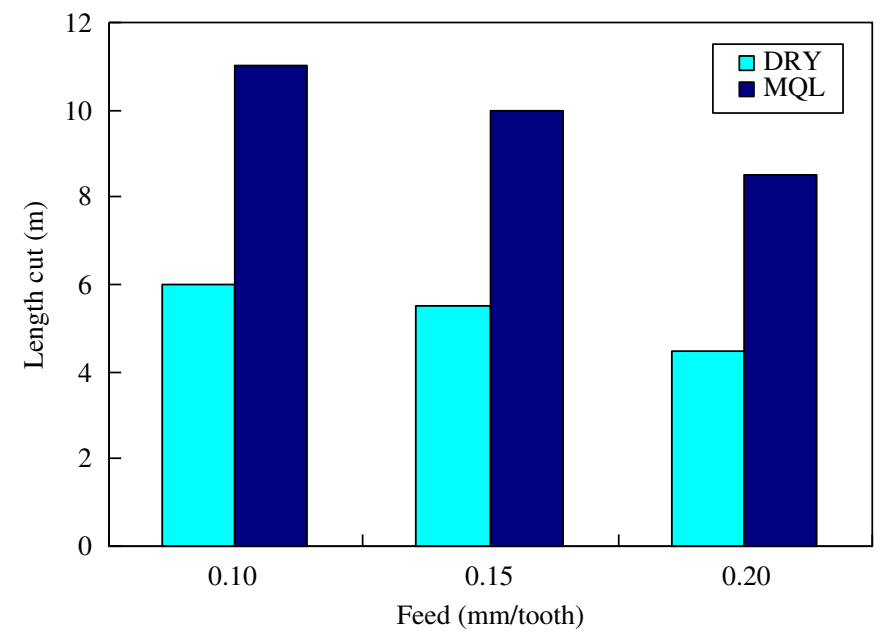

C

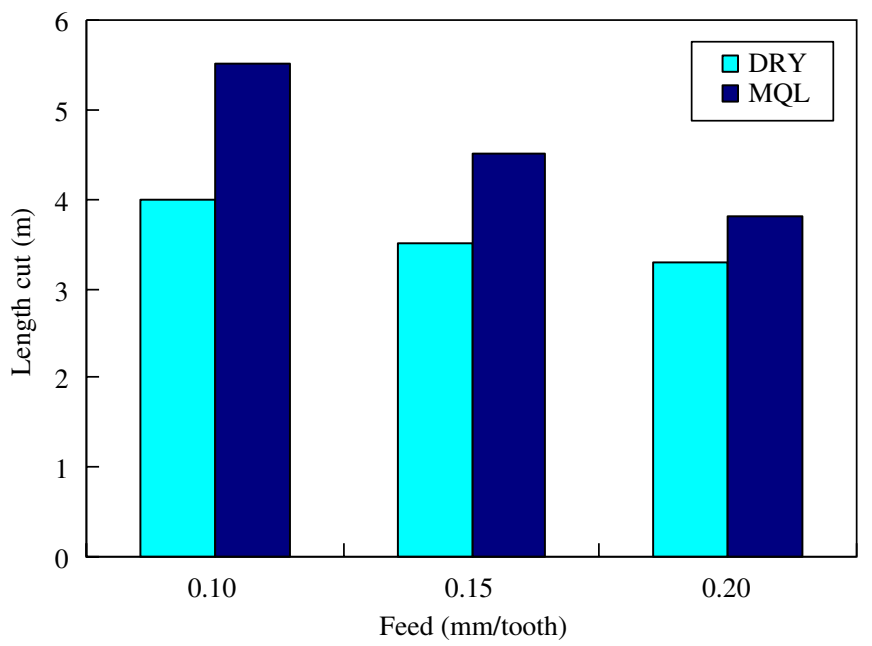

Fig. 1. Tool life as a function of feed rate and cutting environment at various cutting speed with $0.3 \mathrm{~mm}$ depth of cut: (a) $V_{\mathrm{c}}=300 \mathrm{~m} / \mathrm{min}$, (b) $V_{\mathrm{c}}=400 \mathrm{~m} / \mathrm{min}$, and (c) $V_{\mathrm{c}}=500 \mathrm{~m} / \mathrm{min}$.

It was pointed out that diffusion is the dominant tool wear mechanism for carbide tool at high cutting speed condition [3,18-20]. When the machining process is 
conducted at high cutting speed, temperature at the chip-tool interface will increase drastically, especially for cutting hardened steels, and the diffusion between tool and workpiece will be accelerated. As noted by Liao and Shiue [19], when the diffusion of elements ( $\mathrm{Ni}$ or $\mathrm{Fe}$ ) in workpiece into tool's binder $(\mathrm{Co})$ took place, the bonding strength between WC and the binder would be weaken. In addition, Shaw [3] also demonstrates that WC exhibits a high solubility in $\mathrm{Fe}$ and $\mathrm{Ni}$ (5\% and $25 \%$, respectively). This suggests, when the quantity of $\mathrm{Ni}$ and $\mathrm{Fe}$ that diffused into the cutting tool increases, wear resistance of insert will reduce and this in turn accelerates tool wear rate. Hence, if a protective layer can be formed in between the chip-tool interface to retard the mutual diffusion, the strength and wear resistance of a cutting tool would be retained and a longer tool life can be obtained.

The SEM micrographs and EDAX analyses of cutting tools in MQL and dry cuttings under the cutting speed of $300 \mathrm{~m} / \mathrm{min}$ are given in Fig. 2. In comparison with no deposited layer in dry cutting (Fig. 2(a)), an adhering layer on the rake face was clearly seen in MQL cutting (Fig. 2(b)). The EDAX analysis of the WC substrate on site A of Fig. 2(a) in dry cutting is shown in Fig. 2(c). The elements of $\mathrm{Fe}$ and $\mathrm{Ni}$ give evidence of diffusion between workpiece material and cutting tool. Fig. 2(d) is the EDAX analysis for MQL cutting on site B of Fig. 2(b). Except for tiny quantity of $\mathrm{W}$ and $\mathrm{C}$, two-thirds of the compositions are consisted of oxygen and the rest are $\mathrm{Fe}, \mathrm{Mn}, \mathrm{Al}$, and $\mathrm{Si}$. This indicates that the adhering layer is basically composed of complex quaternary oxides, which correspond to the inclusions of the workpiece material.
In order to identify whether the mutual diffusion can be retarded by the oxide layer generated in this study, the layer on site B of Fig. 2(b) was taken away and the EDAX analysis was conducted. The exposed site D in Fig. 3(a) is the region of site B in Fig. 2(b) when the oxide layer was removed, while site $\mathrm{C}$ in Fig. 3(a) is the original region of $\mathrm{C}$ in Fig. 2(b). The EDAX analyses of site $\mathrm{C}$ is shown in Fig. 3(b) and the comparison of chemical composition of sites C and D of Fig. 3(a) and site A of Fig. 2(a) is given in Fig. 3(c). For site $C$ under MQL cutting, the EDAX analysis given in Fig. 3(b) shows that there is no component of Ni; and the quantity of $\mathrm{Fe}$ as shown in Fig. 3(c) is slightly less than that on site A under dry cutting. The elements on site D are the same as those on site $\mathrm{C}$. But their quantities are quite different; there are more $\mathrm{W}$ and $\mathrm{C}$ and less $\mathrm{Fe}$ on the former than those on the latter. In addition, the quantitative distribution of Fe on the WC substrate obtained by the linescanning of EDAX across the sites $\mathrm{C}$ and $\mathrm{D}$ as shown in Fig. 3(d) also reveals a large drop from C to D. Based on the above results, it is concluded that the mutual diffusion of elements can be effectively retarded by the oxide layer formed in this study. This is similar to the finding by Yamane [21] that compound oxides of $\mathrm{Fe}, \mathrm{Mn}, \mathrm{Si}$, and $\mathrm{Al}$ were found to work as a strong barrier for mutual diffusion between steel and carbide tool.

It is noted by Shaw [3] that the generation of a protective oxide layer is determined by the factors including work material, tool material, and cutting speed. Regarding work material, the oxide layer can readily form [21] for steels having a relatively high content of $\mathrm{Si}$ and $\mathrm{Al}$. For the cutting tool materials, carbide and ceramic tools are
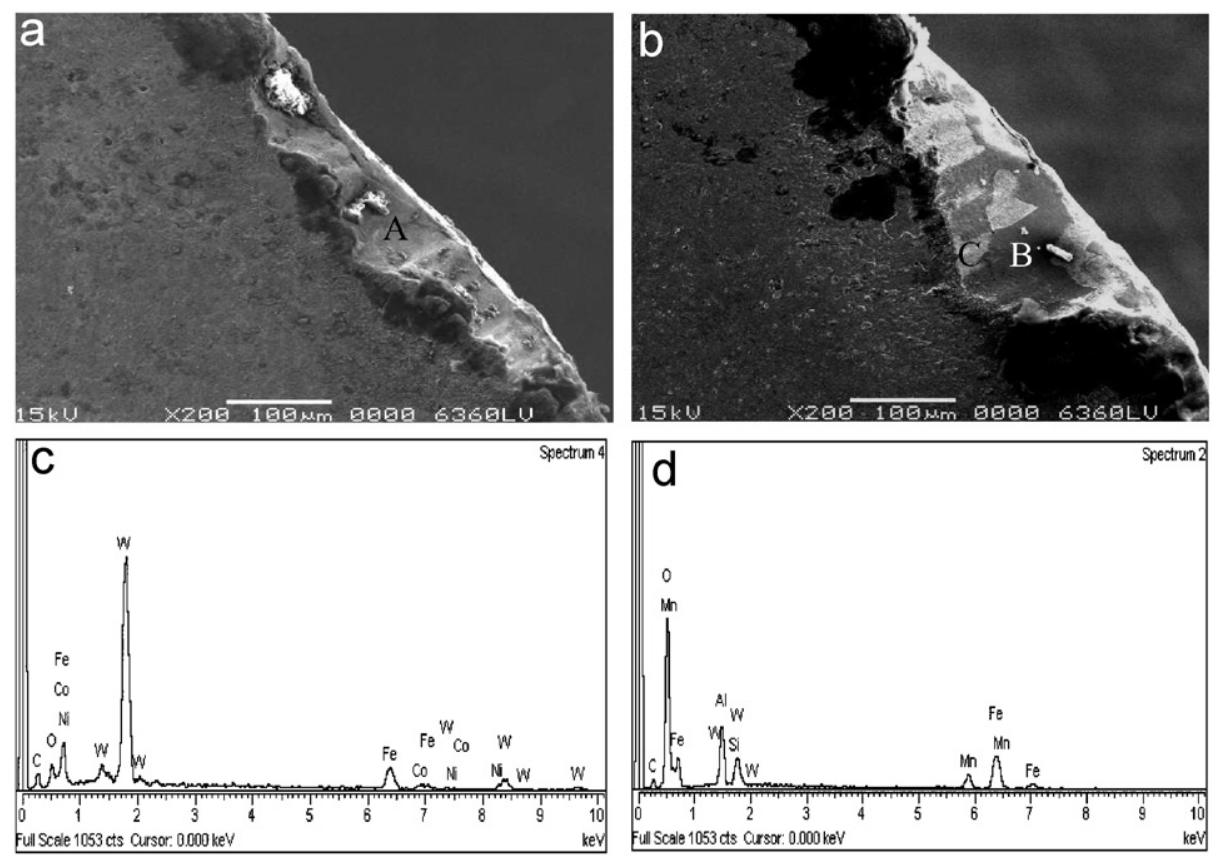

Fig. 2. SEM micrographs on the rake face and EDAX analyses for MQL and dry cutting at $V_{\mathrm{c}}=300 \mathrm{~m} / \mathrm{min}, f_{z}=0.15 \mathrm{~mm} /$ tooth, and $a_{\mathrm{p}}=0.3 \mathrm{~mm}$. (a) SEM micrograph of cutting edges for dry cutting at the ending of cutting. (b) SEM micrograph of cutting edges for MQL cooling at the ending of cutting. (c) EDAX analysis for dry cutting on the site A of part (a). (d) EDAX analysis for MQL on the site B of part (b). 

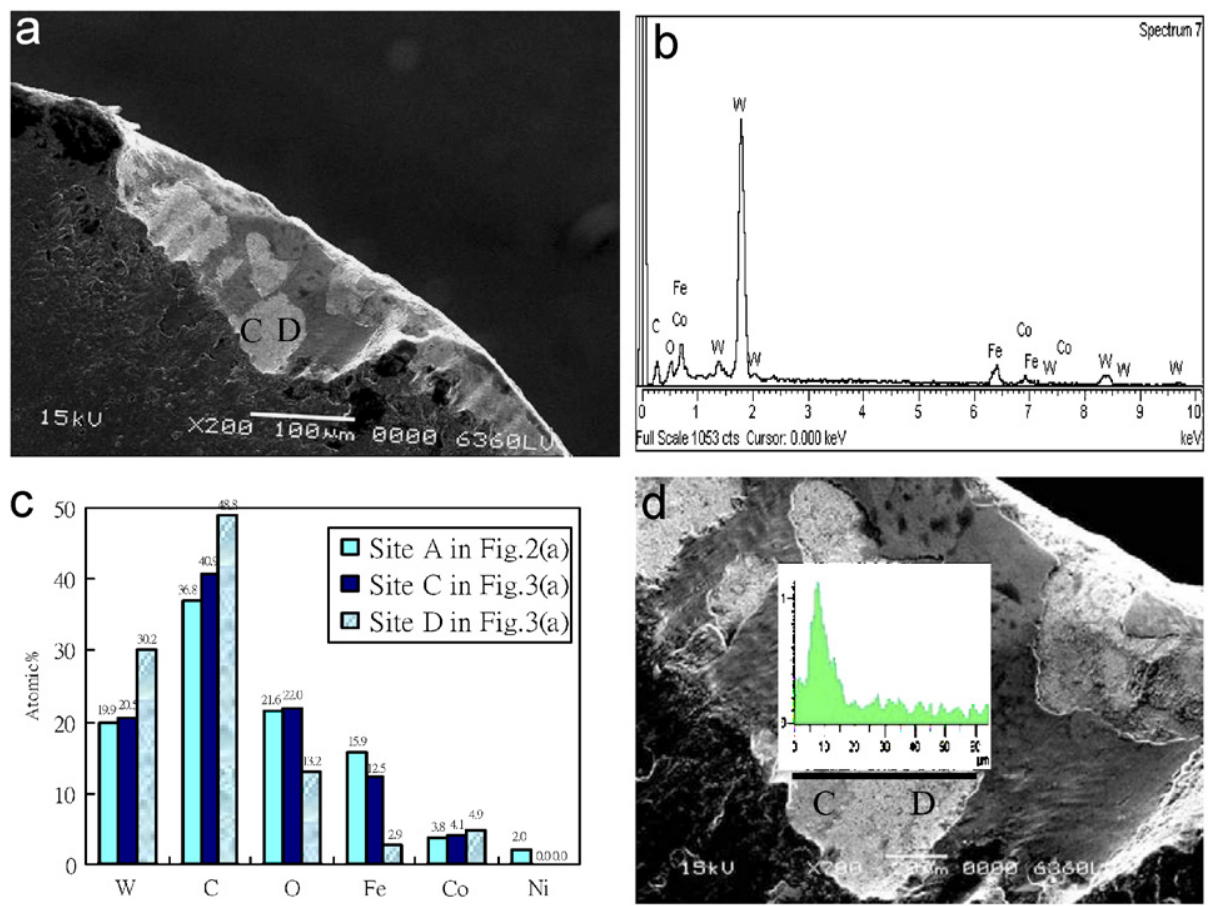

Fig. 3. SEM micrograph and EDAX analyses for MQL and dry cutting at $V_{\mathrm{c}}=300 \mathrm{~m} / \mathrm{min}, f_{z}=0.15 \mathrm{~mm} /$ tooth, and $a_{\mathrm{p}}=0.3 \mathrm{~mm}$, when the oxide layer had been taken away. (a) SEM micrograph of cutting edges for MQL after removing the covered layer on site B of Fig. 2(b). (b) EDAX analysis for MQL on the site $\mathrm{C}$ of part (a). (c) Comparison of chemical composition on WC substrate between site A of Fig. 2(a), site C of part (a), and site D of part (a). (d) The quantitative distribution of $\mathrm{Fe}$ on the WC substrate by the line-scanning of EDAX across the region C and D of part (a).

preferred while HSS is inappropriate [3]. However, Yamane [21] and Bletton et al. [22] had pointed out that this layer would not be effective diffusion barrier if there is insufficient quantity of oxygen. This indicates oxygen supply is another key point to affect the formation of a protective oxide layer.

As for the mechanism involved in forming the protective layer, a hydrodynamic model was proposed by Shaw [3] that a wedge-shaped semi-liquid layer could form between chip and tool interface due to thermal softening of the chip resulted from a high cutting temperature, this in turn leads to a squeeze-film action. The material being cut in this study contains elements of $\mathrm{Si}, \mathrm{Al}$ and $\mathrm{Mn}$ besides Fe. Since the free energy of oxides of $\mathrm{Si}$ and $\mathrm{Al}$ are very low [23], the $\mathrm{Si}$ and $\mathrm{Al}$ in the semi-liquid metal state will react with oxygen to form alumino silicates $\left(\mathrm{SiO}_{2}\right.$ and $\left.\mathrm{Al}_{2} \mathrm{O}_{3}\right)$ preferentially. However, alumino silicates are very stable compounds with very high melting points $\left(1723^{\circ} \mathrm{C}\right.$ for $\mathrm{SiO}_{2}$ and $2020^{\circ} \mathrm{C}$ for $\mathrm{Al}_{2} \mathrm{O}_{3}$ [24]), hence they are difficult to adhere to the cutting tool if no other mechanism is involved. These alumino silicates will be taken away along with chip flow accordingly.

It was proposed by Konig and Diederich [25] that the formation of oxide layer in the machining process could be promoted by oxygen from cutting fluid. The similar suggestion that oils could act as bonding agent to improve the adhesive and film-creating property was presented by Mang and Dresel [26]. Bhushan [27] also demonstrated that the oxidation reaction would be enhanced in a moist atmosphere. The synthetic ester used as the oil of MQL is typically made from the reaction of an organic acid with an alcohol [26,28]. This means that some level of oxygen is included in the synthetic ester due to the bonds of $\mathrm{COO}$ and $\mathrm{OH}$. In addition, when the lubricants are sprayed into small droplets, the content of oxygen in the oil mists will be further increased due to the raised oxidation reaction resulting from the increase of surface area of the lubricant droplets that are in contact with oxygen in the air.

Hence, when MQL is applied, there will be excess oxygen available and oxides of $\mathrm{Fe}$ and $\mathrm{Mn}$ could form as well together with alumino silicates to form quaternary oxides. The melting point of ternary eutectic $\mathrm{FeO}-\mathrm{SiO}_{2}-\mathrm{Al}_{2} \mathrm{O}_{3}$ could be reduced to $1083^{\circ} \mathrm{C}$ [24]. Hence, it is expected that eutectic of quaternary oxides of $\mathrm{Fe}, \mathrm{Mn}, \mathrm{Si}$, and $\mathrm{Al}$ would exhibit an even lower melting point than $1083^{\circ} \mathrm{C}$. Besides, the cutting temperature will be up to $1000^{\circ} \mathrm{C}$ or even higher in HSM [29]. It is deduced that the quaternary oxides are readily melted and thereby leads to the wetting of WC substrate. They adhere to the tool surface simultaneously. It is also noted that the solubility of WC for oxides is comparatively low. Accordingly, the adhesive layer on the WC surface can be acted as an effective diffusion barrier layer to protect the cutting tool from wearing during MQL high-speed cutting. In our experimental results, the tiny quantity of $\mathrm{W}$ and $\mathrm{C}$ on the oxide layer (as described on the EDAX analysis in Fig. 2(d)), more $\mathrm{W}$ and $\mathrm{C}$ and less $\mathrm{Fe}$ under the protective layer as compared to those without a protective layer (site $\mathrm{C}$ vs. site $\mathrm{D}$ in Fig. 3(c)), and the large drop of Fe from site $\mathrm{C}$ to site D displayed in Fig. 3(d), all confirm this inference. In 
contrast, there is no extra oxygen supply to generate oxides of $\mathrm{Fe}$ and $\mathrm{Mn}$ to lower the melting point of the alumino silicates during the dry cutting. Hence, they are taken away by chip flow as already mentioned. This explains why oxide layer is absent under dry cutting.

Based on the above discussions, the role that MQL plays in the formation of the protective layer may be proposed as follows. During the milling process, the tool engaged in metal removal intermittently. In the process of tool disengagement, the oil mists sprayed on the cutting tool are evaporated and left the oil particles on the tool face. When the tool is engaged in cutting, the oil particles adhered to the tool face with abundant oxygen then provide sufficient oxygen for the chip-tool interface to activate the formation of oxide layer. In other words, the MQL can act as a promoter to the formation of the protective layer on the HSM of NAK 80 mold steels.

With respect to the influences of cutting speed, as illustrated in Fig. 1, the improvement of MQL on tool life is less significant under higher speed such as $500 \mathrm{~m} / \mathrm{min}$ condition. Comparing with dry cutting, the reduction of cutting force (Fig. 4(a)) and surface roughness (Fig. 4(b)) by MQL in the higher speed cutting is also smaller than that in the lower speed cutting. These phenomena could be attributed to the extent of oxide layer generated under different cutting speed. The SEM micrographs for MQL under cutting speed of 400 and $500 \mathrm{~m} / \mathrm{min}$ are shown in Fig. 5. The oxide layer for $400 \mathrm{~m} / \mathrm{min}$ given in Fig. 5(a) is less than that for $300 \mathrm{~m} / \mathrm{min}$ in Fig. 2(b). When the cutting speed is further increased to $500 \mathrm{~m} / \mathrm{min}$, there is almost no adhering layer as it is displayed in Fig. 5(b). This may be due to no time available to activate thermal softening of the chip material to form a protective layer as claimed by Shaw [3], or caused by the high friction force which wears away the oxide layer. In the absence of protective layer, severe heat variation would be induced and consequently leads to the initiation of thermal cracks, as shown in marked area of Fig. 5(b), which is detrimental to cutting tool for further machining. This indicates that application of MQL is inappropriate in the extreme high-speed cutting condition. As proposed by Brinksmeier et al. [30], it is essential to select appropriate cutting parameters so as to utilize the potential of MQL. It was suggested also by Tieu et al. [31] that cutting temperature is the most important factor to influence the formation of the adhering layer; and there exists an optimal range of cutting temperature at which a stable layer with largest proportion of inclusion elements could be formed. Based on previous discussions, since the cutting temperature is closely correlated with cutting speed, from practical viewpoint, one might suspect if there exists an optimal cutting speed at which a stable oxide layer can be generated in the MQL machining. In a

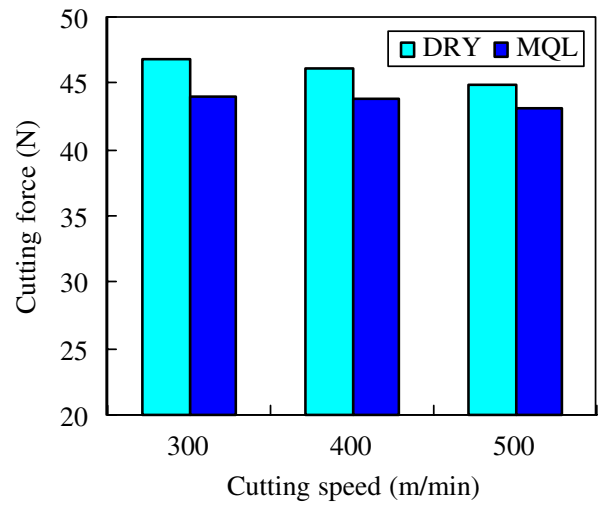

b

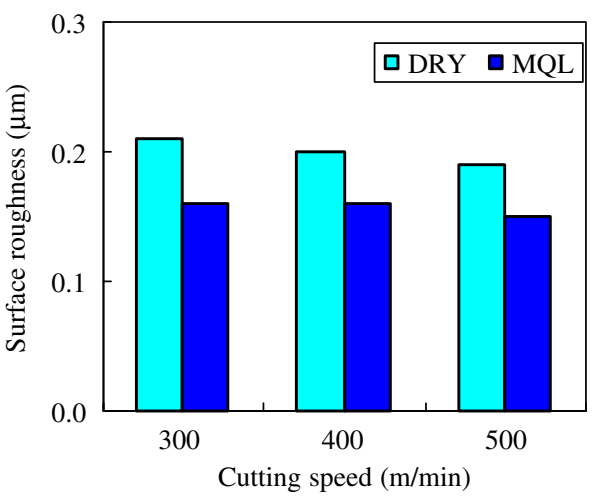

Fig. 4. (a) Cutting force and (b) surface roughness $\left(R_{\mathrm{a}}\right)$ as a function of cutting speed and cutting environment at $0.3 \mathrm{~mm}$ depth of cut and $0.15 \mathrm{~mm} /$ tooth feed rate.
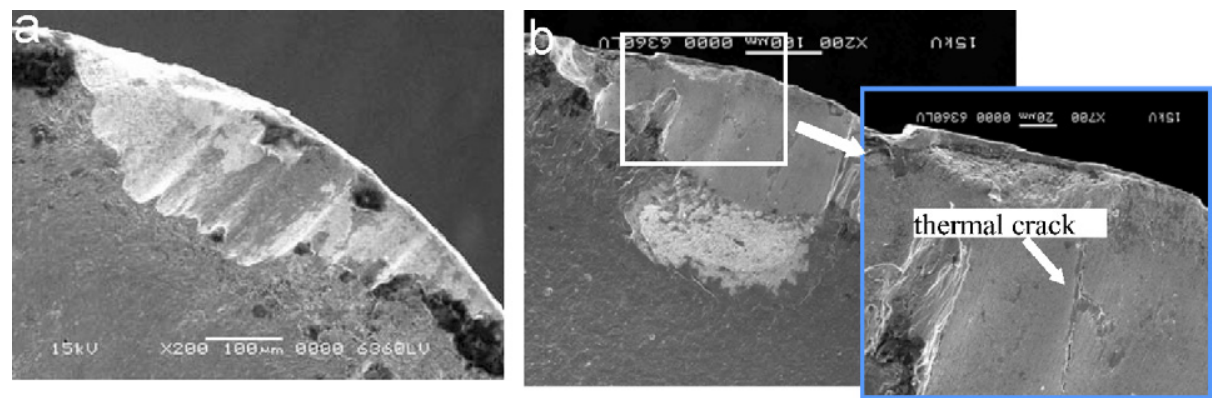

Fig. 5. SEM micrographs for MQL with $0.3 \mathrm{~mm}$ depth of cut and $0.15 \mathrm{~mm} /$ tooth feed rate at cutting speed of: (a) $400 \mathrm{~m} / \mathrm{min}$ and (b) $500 \mathrm{~m} / \mathrm{min}$. 
a

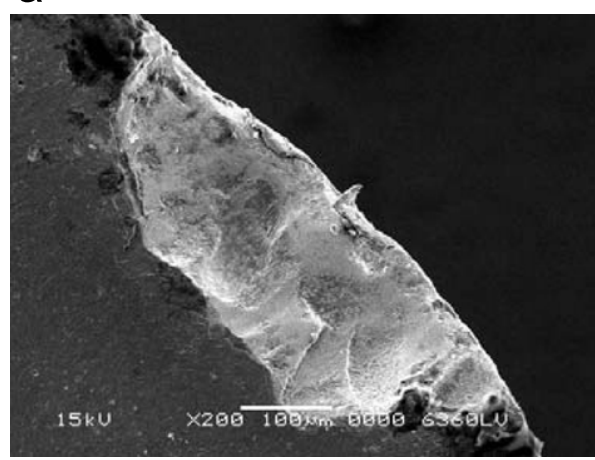

b

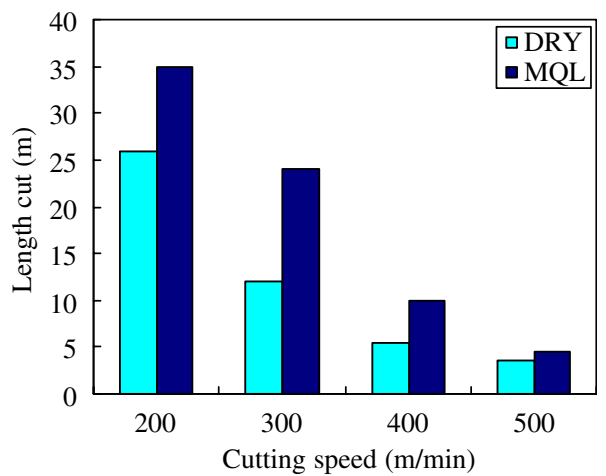

Fig. 6. (a) SEM micrograph for MQL at $V_{\mathrm{c}}=200 \mathrm{~m} / \mathrm{min}, f_{z}=0.15 \mathrm{~mm} /$ tooth, and $a_{\mathrm{p}}=0.3 \mathrm{~mm}$. (b) Comparison of tool life with various cutting speed at $0.3 \mathrm{~mm}$ depth of cut and $0.15 \mathrm{~mm} /$ tooth feed rate.

order to verify this hypothesis, an additional machining test with the application of MQL at cutting speed of $200 \mathrm{~m} /$ $\mathrm{min}$ is conducted. It is found that the oxide layer for $200 \mathrm{~m} /$ min as given in Fig. 6(a) is not as apparent as that of $300 \mathrm{~m} / \mathrm{min}$ in Fig. 2(b). This may be caused by the insufficient energy to induce thermal softening of chips. As a result, the extent of tool life enhancement for cutting speed of $200 \mathrm{~m} / \mathrm{min}$ is less than that of $300 \mathrm{~m} / \mathrm{min}$ (Fig. 6(b)). The foregoing results support the suggestion that there exists an optimal cutting speed, such as around $300 \mathrm{~m} / \mathrm{min}$ in this study, to form a stable oxide layer which leads to a significant improvement of tool performance.

\section{Conclusions}

Experiments are conducted to investigate the mechanism of MQL in HSM of hardened steel comprehensively. It is found that comparing with dry cutting, the tool performance of MQL can be enhanced under all cutting speeds in this study. The role of MQL in HSM of hardened steel is clarified; it could provide extra oxygen to chip-tool interface so as to promote the formation of a protective oxide layer. Besides, there exists an optimal cutting speed, at which a stable oxide layer being proved to act as diffusion barrier can be formed; consequently the strength and wear resistance of cutting tool can be retained and tool life is increased significantly. When the cutting speed is beneath the optimal speed, there is less oxide layer and the enhancement of tool life is less significant accordingly. As the cutting speed is much higher than that of the optimal value, the protective layer was absent, and thermal cracks resulted from large fluctuation of temperature were found on the rake face of cutting tool. Hence, application of MQL is not suggested in the extreme high-speed cutting despite it still results in little increase of tool life.

\section{References}

[1] M.A. Elbestawi, L. Chen, C.E. Becze, T.I. EI-Wardany, High speed milling of dies and models in their hardened state, Annals of CIRP 46 (1) (1997) 57-62.
[2] J.M. Vieira, A.R. Machado, E.O. Ezugwu, Performance of cutting fluids during face milling of steels, Journal of Materials Processing Technology 116 (2001) 244-251.

[3] M.C. Shaw, Metal Cutting Principles, second ed., Oxford, New York, 2005.

[4] K. Weinert, I. Inasaki, J.W. Sutherland, T. Wakabayashi, Dry machining and minimum quantity lubrication, Annals of CIRP 53 (2) (2004) 511-537.

[5] F. Klocke, G. Eisenblatter, Machinability investigation of the drilling process using minimal cooling lubrication techniques, Production Engineering Research and Development in Germany 4 (1) (1997) 19-24.

[6] T. Wakabayashi, H. Sato, I. Inasaki, Turning using extremely small amount of cutting fluids, JSME International Journal, Serials C 41 (1) (1998) 143-148.

[7] A.S. Varadarajan, P.K. Philip, B. Ramamoorthy, Investigations on hard turning with minimal cutting fluid application (HTMF) and its comparison with dry and wet turning, International Journal of Machine Tools and Manufacture 42 (2) (2002) 193-200.

[8] A.E. Diniz, J.R. Ferreira, F.T. Filho, Influence of refrigeration/ lubrication condition on SAE 52100 hardened steel turning at several cutting speeds, International Journal of Machine Tools and Manufacture 43 (3) (2003) 317-326.

[9] R. Heinemann, S. Hinduja, G. Barrow, G. Petuelli, Effect of MQL on the tool life of small twist drills in deep-hole drilling, International Journal of Machine Tools and Manufacture 46 (1) (2006) 1-6.

[10] A. Attanasio, M. Gelfi, C. Giardini, C. Remino, Minimal quantity lubrication in turning: effect on tool wear, Wear 260 (3) (2006) 333-338.

[11] C. Bruni, A. Forcellese, F. Gabrielli, M. Simoncini, Effect of the lubrication-cooling technique, insert technology and machine bed material on the workpart surface finish and tool wear in finish turning of AISI 420B, International Journal of Machine Tools and Manufacture 46 (12-13) (2006) 1547-1554.

[12] N.R. Dhar, M. Kamruzzaman, M. Ahmed, Effect of minimum quantity lubrication (MQL) on tool wear and surface roughness in turning AISI-4340 steel, Journal of Materials Processing Technology 172 (2) (2006) 299-304.

[13] L.R. da Silva, E.C. Bianchi, R.Y. Fusse, R.E. Catai, T.V. Franca, P.R. Aguiar, Analysis of surface integrity for minimum quantity lubricant-MQL in grinding, International Journal of Machine Tools and Manufacture 47 (2) (2007) 412-418.

[14] M. Rahman, A. Senthil Kumar, M.U. Salam, Experimental evaluation on the effect of minimal quantities of lubricant in milling, International Journal of Machine Tools and Manufacture 42 (5) (2002) 539-547.

[15] T. Wakabayashi, I. Inasaki, S. Suda, H. Yokota, Tribological characteristics and cutting performance of lubricant esters for semidry machining, CIRP 52 (1) (2003) 61-64. 
[16] S. Min, I. Inasaki, S. Fujimura, T. Wakabayashi, S. Suda, Investigation of adsorption behaviour of lubricants in near-dry machining, Proceedings of the Institution of Mechanical Engineers, Part B: Journal of Engineering Manufacture 219 (9) (2005) 665-671.

[17] D.A. Axinte, R.C. Dewes, Surface integrity of hot work tool steel after high speed milling experimental data and empirical models, Journal of Materials Processing Technology 127 (2002) 325-335.

[18] E.M. Trent, P.K. Wright, Metal Cutting, Butterworth-Heinemann, London, 2000.

[19] Y.S. Liao, R.H. Shiue, Carbide tool wear mechanism in turning of Inconel 718 superalloy, Wear 193 (1996) 16-24.

[20] J.A. Arsecularatne, L.C. Zhang, C. Montross, Wear and tool life of tungsten carbide, PCBN and PCD cutting tools, International Journal of Machine Tools and Manufacture 46 (5) (2006) 482-491.

[21] Y. Yamane, Tribology in Metal Cutting and Grinding, The Institution of Mechanical Engineers, London, 1993.

[22] O. Bletton, R. Duet, P. Pedarr, Influence of oxide nature on the machinability of 316L stainless steels, Wear 139 (1993) 179-193.

[23] L.S. Darken, R.W. Gurry, M.B. Bever, Physical Chemistry of Metals, McGraw-Hill, New York, 1953.
[24] E.M. Levin, C.R. Robbins, H.F. McMurdie, Phase Diagrams for Ceramists, The American Ceramic Society, Ohio, 1964.

[25] W. Konig, N. Diederich, Cutting fluids improve tool-life of carbide tools by chemical reactions, Annals of CIRP 17 (1969) 17.

[26] T. Mang, W. Dresel, Lubricants and Lubrications, Wiley, Weinheim, 2001.

[27] B. Bhushan, Principles and Applications of Tribology, Wiley, New York, 1999.

[28] L.R. Rudnick, Synthetics, Mineral Oils, and Bio-Based Lubricants: Chemistry and Technology, Taylor \& Francis, Boca Raton, 2006.

[29] S. Dolinsek, B. Sustarsic, J. Kopac, Wear mechanisms of cutting tools in high-speed cutting processes, Wear 250 (2001) 349-356.

[30] E. Brinksmeier, A. Walter, R. Janssen, P. Diersen, Aspects of cooling lubrication reduction in machining advanced materials, Proceedings of the Institution of Mechanical Engineers-Part B-Engineering Manufacture 213 (8) (1999) 769-778.

[31] A.K. Tieu, X.D. Fang, D. Zhang, FE analysis of cutting tool temperature field with adhering layer formation, Wear 214 (2) (1998) 252-258. 